\title{
Identifying and promoting safe walking routes in older adults
}

\author{
Jacqueline Kerr ${ }^{1 *}$, Jordan A. Carlson ${ }^{1}$, Dori E. Rosenberg ${ }^{2}$, Ashley Withers $^{3}$ \\ ${ }^{1}$ Department of Family and Preventive Medicine, University of California San Diego, La Jolla, USA; \\ ${ }^{*}$ Corresponding Author: jkerr@ucsd.edu \\ ${ }^{2}$ Group Health Research Institute, Seattle, USA \\ ${ }^{3}$ Graduate School of Public Health, San Diego State University, San Diego, USA
}

Received 17 July 2012; revised 15 August 2012; accepted 26 August 2012

\section{ABSTRACT}

Background: Walking for physical activity is important for older adults' physical and mental health. We developed and tested the reliability of an environmental audit tool designed to be used by lay people to identify appropriate walking routes for older adults trying to increase their physical activity. Methods: A 44-item Walking Route Audit Tool for Seniors (WRATS) was developed based on literature review and input from older adults during focus groups. Observers completed the tool for 24 walking routes which were specifically selected to maximize variability in environment features and quality. Inter-rater reliability was assessed using Kappa and percent agreement. Results: Inter-rater reliability was good to excellent for 27 of the 44 WRATS items and moderate for 9 items. ICCs were good to excellent for 6 of the 8 scales (ICCs $=0.61$ to 0.90 ). Conclusions: These results provide evidence for the reliability of WRATS for evaluating environmental attributes of walking routes suitable for older adults. Some scales need further refinement, and validity should be tested in a sample of older adults.

Keywords: Older Adults; Walkability; Physical Activity

\section{INTRODUCTION}

Walking is a popular, inexpensive, and low impact way for older adults to meet physical activity guidelines [1]. The health benefits of walking in older adults include decreased blood pressure, increased cardiovascular function, better balance and strength, increased stamina, and improvements in mental health and overall quality of life, among others [2]. However, only $2.5 \%$ of the popu- lation over 60 years old meets physical activity recommendations of at least 30 minutes of moderate-intensity physical activity on 5 days per week or 150 minutes per week [3].

Research has shown that walking in older adults, whether for leisure or transportation purposes, is positively related to environmental features such as destinations, greenery, access to transit, safety of street crossings, lighting, traffic calming, rest spots, curbs, and sidewalk maintenance [4]. A walking route can be defined as the path taken to get from one point of interest to another as well as a loop starting and ending at the same location. Since environmental features can vary from route to route, and since these features influence safety, enjoyment and maintenance of walking, it is important for older adults to choose the most appropriate routes when walking.

Assessing environments for their "walking supportiveness" can help promote the best and safest routes to travel as well as highlight areas that are in need of improvement. Existing tools have been developed to evaluate walking environments but are lengthy, complicated because they have variable response options, are meant to be used by researchers rather than the general population, assess segments rather than a whole route, or do not include environment features specifically salient to older adults [5-7]. The aim of the present study was to develop and evaluate the reliability of the Walking Routes Audit Tool for Seniors (WRATS) in attempt to fill the aforementioned gaps in environmental audit tools. WRATS was designed to be simple (e.g., yes/no response options), brief (i.e., 44 items) and relevant to older adults looking for appropriate and safe walking routes.

\section{METHODS}

\subsection{Procedures}

Literature review. Urban planning and physical activity literature was reviewed, including correlation studies 
and existing tools [5-7], and important concepts were identified to inform development of the WRATS. Four main domains of environmental determinants of walking in older adults were identified [2]: functionality, which reflects structural aspects of the environment (i.e. path attributes, type/width of street, buildings); safety, which reflects both personal (i.e. lighting, surveillance) and traffic safety (i.e. marked crosswalks); aesthetics, which reflects the quality and visual appeal of surroundings (i.e. trees, parks, pollution); and destinations, which refer to the availability of services and places to walk (i.e. shops, restaurants, public transport).

Focus Groups. Two focus groups were conducted with 7 - 8 older adults ( $\geq 74$ years of age) in each group. Content analysis was performed and several environmental barriers to walking were identified, including hills, safety (e.g., curb ramps, crosswalks, sidewalk condition) and aesthetics. Feedback from the focus groups was used to ensure adequate coverage of aspects of the built environmental considered important to older adults. Ethical approval was granted by the sponsoring university's Internal Review Board, and participants signed informed consent to participate.

\subsection{Measures}

The WRATS tool was drafted by two of the authors of this paper based on information obtained from the literature review and focus groups. The tool included 44 items and was organized into 6 sections. Each section had 1 - 2 scales that included items that were hypothesized to be either positively or negatively related to walking in older adults. The sections were features/functionality (7 negative items); traffic safety ( 5 positive and 7 negative items); amenities (6 positive items); aesthetics ( 7 positive items); personal safety ( 3 positive and 3 negative items); and destinations (6 positive items). For all items, the wording stem was "did you see". Response options were never, sometimes, or often but were recoded to yes/no to improve simplicity of the tool.

\subsection{Data Collection}

Walking routes were selected to represent a range in income (from census data) and walkability (intersections density). Routes were chosen to be approximately 0.5 to 1.5 miles in length and both one-way and loop (i.e., start and finish in same location) routes were included. Four undergraduate students were chosen to be raters because they were not experienced in measuring built environments, similar to a lay community member. Raters were given a brief introduction to the tool and four practice routes after which differences in ratings were discussed. No other training was provided. Two raters walked each route at the same time but completed the WRATS inde- pendently. To approximate distance of each route, raters wore pedometers (Accusplit health engine) which measured step count during the walk.

\subsection{Analysis}

Inter-rater reliability was assessed for the 44 WRATS items using Kappa and percent agreement [8]. Low variability in item responses can lead to a high expected agreement. In such circumstances, Kappa may be small even given a high observed agreement because the difference between the observed and expected agreement will be small (i.e., the numerator of the Kappa equation). Accordingly, percent agreement was exclusively used to infer reliability when the item had low variability, defined as expected agreement $\geq 0.70$. The following criteria were employed: Kappa $\geq 0.60$ or $\geq 75 \%$ agreement (if low variability) was interpreted as good to excellent reliability; Kappa $0.40-0.59$ or $\geq 70 \%$ agreement (if low variability) was interpreted as moderate reliability; and Kappa $<0.40$ and $<70 \%$ agreement (if low variability) was interpreted as fair to poor reliability [8]. Eight scales were calculated by dividing the sum of the number of "yes" responses by the total number of items in the scale and descriptive statistics were examined. One-way random effects single rater interclass correlation coefficients (ICCs) were used to assess inter-rater reliability for the scales and interpreted using the same criteria for Kappa.

\section{RESULTS}

Twenty-four routes were selected from 23 census tracts. Census tract income where the routes were located ranged from $\$ 20,445$ to $\$ 72,297(\mathrm{M}=\$ 37,777 ; \mathrm{SD}=$ $\$ 13,198)$ and intersections/route ranged from 2 - $15(\mathrm{M}=$ 8.3; $\mathrm{SD}=3.5$ ). Route step count ranged from 698 to $2695(\mathrm{M}=1672 ; \mathrm{SD}=488)$, distances that older adults might walk.

Table 1 provides inter-rater reliability values for the individual WRATS items. Seventeen of the 44 WRATS items had low variability; but percent agreement ranged from $70.8 \%$ to $100 \%$ for these items. For the remaining 27 items, Kappa ranged from 0.13 to 1.00 . Twenty-seven of the 44 items had a Kappa $\geq 0.60$ or $\geq 75 \%$ agreement (if low variability), indicating good to excellent reliability, and 9 items had a Kappa of $0.40-0.59$ or $\geq 70 \%$ agreement if low variability, indicating moderate reliability.

Four items from the traffic safety scale had poor reliability; these items dealt with street crossing time, street crossing view, amount of traffic, and height of curb drop. Other items displaying poor reliability addressed sheltered area, gardens/green areas, artwork, and street lamps. ICCs for WRATS scales ranged from 0.34 to 0.90 , and 6 of the 8 scales had an ICC $\geq 0.60$, indicating good to excellent reliability (see Table 2). Mean scores for WRATS 
Table 1. Inter-rater reliability for WRATS items $(\mathrm{N}=24)$.

\begin{tabular}{|c|c|c|c|}
\hline Item Content (Yes/No) & Kappa & $\%$ Agreement & Summary ${ }^{*}$ \\
\hline \multicolumn{4}{|l|}{ Features/Functionality } \\
\hline No sidewalk or paved path & 0.74 & 87.5 & G-E \\
\hline Broken or cracked sidewalks & $0.47^{\dagger}$ & 91.7 & G-E \\
\hline Sidewalks or paths entirely blocked & 0.70 & 91.7 & G-E \\
\hline Sidewalks or paths partially blocked & 0.51 & 75.0 & Mod \\
\hline Slope, hill, or steep incline & 0.73 & 87.5 & G-E \\
\hline Construction/road works & 1.00 & 100 & G-E \\
\hline Stairs & $0.00^{\dagger}$ & 100 & G-E \\
\hline \multicolumn{4}{|l|}{ Traffic Safety } \\
\hline Resting island half way across & $0.33^{\dagger}$ & 79.2 & G-E \\
\hline Marked crosswalks on roads crossed & 0.44 & 75.0 & Mod \\
\hline Controllable pedestrian signals on roads crossed & 0.57 & 79.2 & Mod \\
\hline Automatic pedestrian signals on roads crossed & 0.44 & 75.0 & Mod \\
\hline Speed humps & $0.00^{\dagger}$ & 83.3 & G-E \\
\hline Many lanes/wide road on roads crossed & 0.42 & 70.8 & Mod \\
\hline Insufficient crossing time on roads crossed & 0.32 & 70.8 & F-P \\
\hline Too much traffic on roads crossed & 0.39 & 70.8 & F-P \\
\hline Things blocking view on roads crossed & 0.31 & 66.7 & F-P \\
\hline Inconsiderate/dangerous drivers on roads crossed & 0.60 & 83.3 & G-E \\
\hline High curb/drop onto street on crossed roads & 0.36 & 70.8 & F-P \\
\hline Traffic/noise pollution & $0.18^{\dagger}$ & 70.8 & Mod \\
\hline \multicolumn{4}{|l|}{ Amenities } \\
\hline Sheltered area along route & 0.13 & 62.5 & F-P \\
\hline Public restrooms along route & $0.65^{\dagger}$ & 95.8 & G-E \\
\hline Drinking fountain along route & $0.00^{\dagger}$ & 95.8 & G-E \\
\hline Public transport stop/station along route & 0.51 & 75.0 & Mod \\
\hline Exercise stations along route & $0.00^{\dagger}$ & 100 & G-E \\
\hline Benches along route & 0.44 & 70.8 & Mod \\
\hline \multicolumn{4}{|l|}{ Aesthetics } \\
\hline Nice homes/buildings along route & 0.78 & 95.8 & G-E \\
\hline Trees along route & $0.00^{\dagger}$ & 100 & G-E \\
\hline Nice gardens/green areas along route & 0.32 & 70.8 & F-P \\
\hline Nice shop fronts along route & 0.82 & 91.7 & G-E \\
\hline Water features along route & 0.86 & 95.8 & G-E \\
\hline Artwork/sculptures along route & 0.32 & 70.8 & F-P \\
\hline Shade & $0.00^{\dagger}$ & 87.5 & G-E \\
\hline \multicolumn{4}{|l|}{ Personal Safety } \\
\hline Neighborhood watch signs along route & $0.78^{\dagger}$ & 95.8 & G-E \\
\hline Street lamps along route & 0.34 & 75.0 & F-P \\
\hline Other people along route & 0.63 & 83.3 & G-E \\
\hline Scary/unfriendly people & 0.71 & 87.5 & G-E \\
\hline Litter/graffiti & 0.46 & 0.75 & Mod \\
\hline Scary/unfriendly dogs & $0.50^{\dagger}$ & 87.5 & G-E \\
\hline \multicolumn{4}{|l|}{ Destinations } \\
\hline Park & $0.65^{\dagger}$ & 95.8 & G-E \\
\hline Shops & 0.66 & 83.3 & G-E \\
\hline Service e.g. medical, library, postal & $0.50^{\dagger}$ & 87.5 & G-E \\
\hline Church & $0.83^{\dagger}$ & 95.8 & G-E \\
\hline Friend's house & $1.00^{\dagger}$ & 100 & G-E \\
\hline Senior center or recreation facility & $1.00^{\dagger}$ & 100 & G-E \\
\hline
\end{tabular}

${ }^{*} \mathrm{G}-\mathrm{E}=$ good to excellent reliability (Kappa $\geq 0.60$ or $\geq 75 \%$ agreement if low variability), Mod $=$ moderate reliability (Kappa $=0.40-0.59$ or $\geq 70 \%$ agreement if low variability), F-P = fair to poor reliability (Kappa $<0.40$ and $<70 \%$ agreement if low variability); ${ }^{\dagger}$ Item had low variability defined by expected agreement $\geq 0.70$. 
Table 2. Inter-rater reliability and descriptive statistics for WRATS scales $(\mathrm{N}=24)$.

\begin{tabular}{lcccccc}
\hline \multicolumn{1}{c}{ Scale } & \# Items & \# Items G-E $^{*}$ & \# Items Mod $^{\dagger}$ & ICC & Mean (SD) & Range \\
\hline Features/functionality (negative) & 7 & 6 & 1 & 0.85 & $0.37(0.21)$ & $0.07-0.86$ \\
Traffic safety (positive) & 5 & 2 & 3 & 0.34 & $0.38(0.24)$ & $0.00-0.80$ \\
Traffic safety (negative) & 7 & 1 & 2 & 0.61 & $0.43(0.27)$ & $0.00-1.00$ \\
Amenities (positive) & 6 & 3 & 2 & 0.76 & $0.29(0.18)$ & $0.00-0.58$ \\
Aesthetics (positive) & 7 & 5 & 0 & 0.77 & $0.66(0.19)$ & $0.21-1.00$ \\
Personal safety (positive) & 3 & 2 & 0 & 0.62 & $0.51(0.23)$ & $0.00-0.83$ \\
Personal safety (negative) & 3 & 2 & 1 & 0.56 & $0.38(0.27)$ & $0.00-1.00$ \\
Destinations (positive) & 6 & 6 & 0 & 0.90 & $0.23(0.24)$ & $0.00-0.83$ \\
Total $^{\S}$ & 44 & 27 & 9 & 0.80 & $0.03(0.22)$ & $-0.37-0.46$ \\
\hline
\end{tabular}

${ }^{*} \mathrm{G}-\mathrm{E}=$ good to excellent reliability (Kappa $\geq 0.60$ or $\geq 75 \%$ agreement if low variability); ${ }^{\dagger}$ Mod $=$ moderate reliability $(\mathrm{Kappa}=0.40-0.59$ or $\geq 70 \%$ agreement if low variability); ${ }^{\ddagger}$ Scores were averaged across raters; ${ }^{\circledR}$ Calculated by taking the sum of the positive scales minus the sum of the negative scales.

scales ranged from 0.23 to 0.66 . Aesthetics (positive) and personal safety (positive) had the highest mean scores among the scales.

\section{DISCUSSION}

These results support the inter-rater reliability of WRATS to assess walking routes intended to be appropriate and safe for older adults. Reliability was moderate to excellent for $81.8 \%$ of the items and good to excellent for $61.4 \%$ of the items. All but 2 scales, traffic safety (positive) and personal safety (negative), had good to excellent inter-rater reliability.

A majority of the items that displayed poor reliability involved more subjectivity in ratings than WRATS items with greater reliability. For example, "too much" traffic, "insufficient" crossing time, and "nice" gardens could be interpreted differently by different raters and thus had poorer reliability. These items may benefit from more objective wording or clearer definitions. However, not all items with subjectivity had poor reliability (e.g., nice homes, nice shop fronts). Furthermore, subjectivity in items can reflect a person's perceptions of the environment, which can be as or more important than objective assessments [9]. A majority of the 17 WRATS items with low variability were endorsed in $<10 \%$ or $>90 \%$ of the routes. Although these features did not vary sufficiently for statistical analyses, they may still be important in choosing a walking route for older adults. Thus, many of these items, such as shade, speed humps, and traffic pollution should be retained in the WRATS tool. Other items with low variability, such as broken or cracked sidewalks, may benefit from clearer definitions.

The present study was limited by utilizing a small sample of raters and routes, and by using college students as raters as opposed to community members or older adults. Further studies should assess the validity of WRATS for determining appropriate routes for older adults and the usability of the WRATS in a population of older adults. WRATS has been employed to identify walking routes for older adults in two intervention studies designed to increase neighborhood walking in seniors, but research staff performed the audits rather than community support staff or older adults themselves $[10,11]$.

Identifying appropriate walking routes for older adults is important for promoting physical activity and successful aging. While it may be ideal for older adults to live in more walkable neighborhoods with access to helpful destinations, even those living in low walkable neighborhoods may have one or two excellent walking routes available, particularly for leisure walking. The present study found that WRATS has adequate inter rater reliability for assessing walking environment features salient to older adults. Recommendations are for community leaders (e.g., support staff) working with older adults to consider using WRATS to identify best walking routes as well as areas in need of improvement.

\section{REFERENCES}

[1] Nelson, M.E., Rejeski, W.J, Blair, S.N., Duncan, P.W., Judge, J.O., King, A.C., Macera, C.A. and CastanedaSceppa, C. (2007) Physical activity and public health in older adults: Recommendation from the American College of Sports Medicine and the American Heart Association. Medicine \& Science in Sports \& Exercise, 39, 14351445. doi:10.1249/mss.0b013e3180616aa2

[2] National Institute of Health (2002) NIH senior health: Exercise for older adults. http://nihseniorhealth.gov/exercise

[3] Troiano, R.P., Berrigan, D., Dodd, K.W., Masse, L.C., Tilert, T. and McDowell, M. (2008) Physical activity in the United States measured by accelerometer. Medicine \& Science in Sports \& Exercise, 40, 181-188.

[4] Van Cauwenberg, J., De Bourdeaudhuij, I., De Meester, F., Van Dyck, D., Salmon, J., Clarys, P. and Deforche, B. (2011) Relationship between the physical environment and physical activity in older adults: A systematic review. Health \& Place, 17, 458-469. doi:10.1016/j.healthplace.2010.11.010

[5] Cunningham, G.O., Michael, Y.L., Farquhar, S.A. and 
Lapidus, J. (2005) Developing a reliable senior walking environmental assessment tool. American Journal of Preventive Medicine, 29, 215-217. doi:10.1016/j.amepre.2005.05.002

[6] Day, K., Boarnet, M., Alfonzo, M. and Forsyth, A. (2006) The Irvine-Minnesota inventory to measure built environments: Development. American Journal of Preventive Medicine, 30, 144-152. doi:10.1016/j.amepre.2005.09.017

[7] Pikora, T.J., Giles-Corti, B., Knuiman, M.W., Bull, F.C., Jamrozik, K. and Donovan, R.J. (2006) Neighborhood environmental factors correlated with walking near home: Using SPACES. Medicine \& Science in Sports \& Exercise, 38, 708-714. doi:10.1249/01.mss.0000210189.64458.f3

[8] Landis, J.R. and Koch, G.G. (1977) The measurement of observer agreement for categorical data. Biometrics, 33, 159-174. doi: $10.2307 / 2529310$

[9] Rosenberg, D., Kerr J., Sallis, J., Patrick. K., Norman, G. and Calfas, K. (2012) Promoting walking among older adults living in retirement communities. Journal of Aging and Physical Activity, 20, 379-394.

[10] Gebel, K., Bauman, A. and Owen, N. (2009) Correlates of non-concordance between perceived and objective measures of walkability. Annals of Behavioral Medicine, 37, 228-238. doi:10.1007/s12160-009-9098-3

[11] Rosenberg, D., Kerr, J., Sallis, J., Patrick, K., Moore, D. and King, A. (2009) Feasibility and outcomes of a multilevel place-based walking intervention for seniors: A pilot study. Health \& Place, 15, 173-179. doi:10.1016/j.healthplace.2008.03.010 